\title{
Equatorial sporadic $E$-layer abnormal density enhancement during the recovery phase of the December 2006 magnetic storm: A case study
}

\author{
L. C. A. Resende and C. M. Denardini
}

Aeronomy Division, National Institute for Space Research, P. O. Box 515, S. J. Campos, SP, Brazil

(Received March 23, 2011; Revised October 12, 2011; Accepted October 18, 2011; Online published May 25, 2012)

\begin{abstract}
Sporadic layers appear in the equatorial region $\left(E_{\mathrm{sq}}\right)$ between 90 and $130 \mathrm{~km}$ mainly due to irregularities in the electrojet equatorial (EEJ) current. In the present work, we have analyzed the behavior of the frequency parameters associated with these sporadic layers, covering the days before, during, and subsequent to, the intense magnetic storm that occurred on December 14, 2006. The parameters used in our analyses are the top frequency $\left(f_{\mathrm{t}} E_{\mathrm{s}}\right)$ and blanketing frequency $\left(f_{\mathrm{b}} E_{\mathrm{s}}\right)$ of the $E_{\mathrm{s}}$ layer as measured over São Luís, Brazil $\left(2.33^{\circ} \mathrm{S}, 44.2^{\circ} \mathrm{W}\right.$, dip: $-4.5^{\circ}$ ) by digital ionosonde. A tentative association between these parameters and X-ray data measured by sensors on board the GOES satellite was carried out. Also, we investigated the effects on the dynamics of the equatorial electrojet using magnetometer data related to the presence of these $E_{\mathrm{s}}$ layers. Our analyses show that there are notable changes in the $f_{\mathrm{b}} E_{\mathrm{s}}$, which are characterized by the occurrence of peaks that exceed the ambient background values.
\end{abstract}

Key words: Space weather, sporadic $E$-layer, magnetic storms, equatorial latitude.

\section{Introduction}

Typical sporadic $E$ layers $\left(E_{\mathrm{s}}\right)$ are very narrow (normally $2-10 \mathrm{~km}$ in height) layers of ionization enhancements with respect to the ambient ionization density. They are normally observed in the $E$-region in the height range between 90 and $130 \mathrm{~km}$ and are quite wide horizontally (covering tens to hundreds of kilometers). They are characterized by a large day-to-day variability and distinct features depending on the altitude and latitude where they are observed. $E_{\mathrm{s}}$ layers are detected in ionograms due to reflections in the thin layer of plasma density enhancement due to long-lived metallic ions such as $\mathrm{Fe}^{+}, \mathrm{Mg}^{+}, \mathrm{Ca}^{+}$and $\mathrm{Na}^{+}$(Tsunoda, 2008). The layer density can be up to an order of magnitude greater than background densities, mainly because their lifetime is longer than the dominant species $\left(\mathrm{O}^{+}, \mathrm{NO}^{+}, \mathrm{O}_{2}{ }^{+}\right)$at the $E$-region heights (Kopp, 1997).

Based on HF sounders, several different types of $E_{\mathrm{s}}$ have been detected and their classification is based primarily on their appearance in ionograms, taking into account the transparent, or blanketing, nature and the location. The formation mechanisms have been understood only later. The blanketing frequency $E_{\mathrm{s}}$ layers ( $\left.E_{\mathrm{sb}}\right)$ (Tsunoda, 2008) were originally classified as being of several types, and were labeled as follows: "f" (flat, a nocturnal type of $E_{\mathrm{s}}$ ), "l" (low, a diurnal type of $E_{\mathrm{s}}$ ), "c" (cusp, connected to the end of the $E$-layer trace), "h" (high, observed at higher altitudes), and "a" (auroral). The development of $E_{\mathrm{s}}$-a layers are strongly associated with particle precipitation at high latitudes (Sauli and Bourdillon, 2008). In a comprehensive study of middle

Copyright (C) The Society of Geomagnetism and Earth, Planetary and Space Sciences (SGEPSS); The Seismological Society of Japan; The Volcanological Society of Japan; The Geodetic Society of Japan; The Japanese Society for Planetary Sciences; TERRAPUB.

doi: $10.5047 /$ eps.2011.10.007 and low latitudes, Whitehead (1989) stated that $E$-region ionization enhancements $\left(E_{\mathrm{s}}-1,-\mathrm{f},-\mathrm{c},-\mathrm{h}\right)$ can be formed due to vertical shear caused by opposing horizontal neutral winds. Such a shear can be driven by gravity waves (Hook, 1970; Jayachandran, 1991; Lanchester et al., 1991) or tidal motions (Chimmonas, 1971).

In the equatorial region, the most frequently-observed type of $E_{\mathrm{s}}$ layer is the type "q" (equatorial). Despite the fact that this kind of signature in the ionograms does not indicate a layer in the sense of resulting in an enhancement of the electron density, and does not block signals reflected at the upper regions, it is classified as an $E_{\mathrm{s}}$ layer in ionosphere research based on ionosondes (Piggot and Rawer, 1972). Indeed, the $E_{\mathrm{sq}}$ layer is associated with equatorial electrojet (EEJ) current instabilities (Fejer and Kelley, 1980; Forbes, 1981). The signatures of the $E_{\mathrm{sq}}$ layers in ionograms appears as a scattering of the ionosonde signal covering most of the frequency scale, and occurs during daylight time. Knecht and Mcduffie (1969) showed that the $E_{\mathrm{sq}}$ can be detected over a distance of about $700 \mathrm{~km}$ in latitude around the magnetic equator, which agrees with the width of the equatorial geomagnetic field enhancements observed with a magnetometer. However, it must be noted that $E_{\mathrm{sq}}$ layers may be observed simultaneously with other

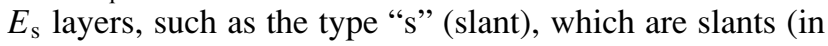
height) that emerge in the original layer trace (Cohen et al., 1962). A more comprehensive review on $E_{\mathrm{s}}$ layers has been published by Whitehead (1970).

Studies of the presence of $E_{\mathrm{s}}$ layers during periods of disturbance have being carried out by Batista and Abdu (1977) at low latitudes in the Brazilian sector. They compiled the total frequency $\left(f_{\mathrm{t}} E_{\mathrm{s}}\right)$, and the blanketing frequency $\left(f_{\mathrm{b}} E_{\mathrm{s}}\right)$, of $E_{\mathrm{s}}$ layers during several magnetic storms during the solar cycle 20 and stated that $f_{\mathrm{b}} E_{\mathrm{s}}$ show a well-defined en- 


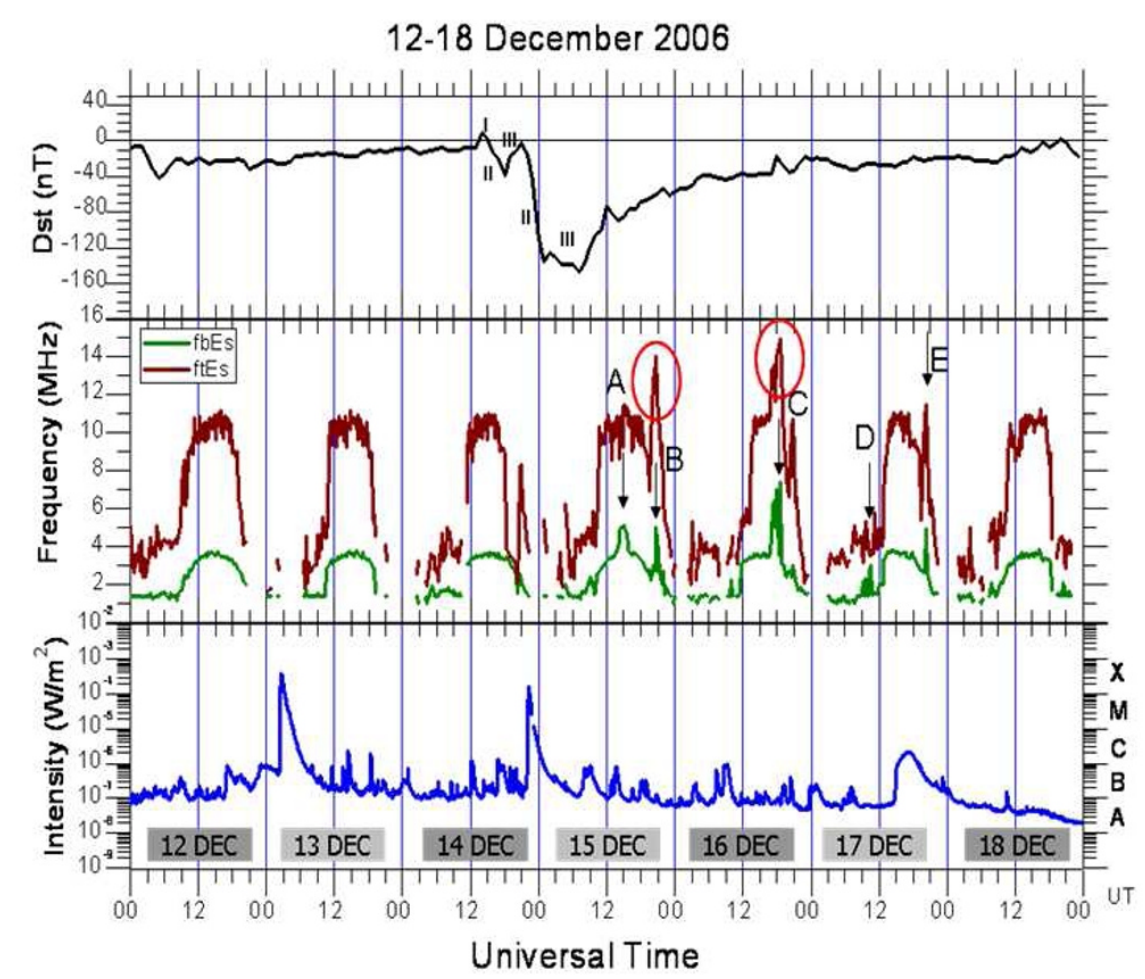

Fig. 1. The figure shows three panels with the variation of the $D_{\mathrm{st}}$ index on the top, the variation of the $f_{\mathrm{b}} E_{\mathrm{s}}\left(\right.$ green line) and $f_{\mathrm{t}} E_{\mathrm{s}}(\mathrm{brown}$ line) at São Luís in the middle panel, and the variation of the X-ray solar radiation intensity measured in the range $1.0-8.0 \AA$ (blue line) from December 12 to 18 , 2006 (bottom panel).

hancement of appreciable magnitude, observed 1-3 days after the Sudden Commencement (SC) of the storms. Also, Afraimovich et al. (2001) established that extreme solar flares may cause sudden changes in ionospheric ionization, which can lead to global distribution changes. They show that enhancements of X-ray and UV radiation intensity, that are observed during chromospheric flares, cause sudden increases in the process of the formation of free electrons, increasing the electron density in ionospheric layers.

In the present paper, the variation of $f_{\mathrm{t}} E_{\mathrm{s}}$ and $f_{\mathrm{b}} E_{\mathrm{s}}$, obtained from a digital sounder at São Luís during the days before, during, and subsequent to, the December 2006 magnetic storm, are studied. Specifically, we have studied the abnormal density enhancement in the $f_{\mathrm{b}} E_{\mathrm{s}}$ that are discussed in terms of the magnetic activity. Furthermore, we have also checked for a direct relationship between the occurrence of flares and $E$ layer density enhancement, during the magnetic storm, using $f_{\mathrm{b}} E_{\mathrm{s}}$ as a proxy of $f_{\mathrm{o}} E$.

\section{Instrumentation}

We have used data from two different types of groundbased equipment installed on, and close to, the dip equator in the Brazilian sector: a digital ionosonde and two magnetometers. Data from digital sounders at São Luís, an equatorial station, were used to determine the ionospheric frequency parameters mentioned previously. It operated every 15 minutes, sending consecutive pulses in the frequency range from 0.5 to $30 \mathrm{MHz}$, in steps of $0.5 \mathrm{MHz}$.

The Earth's magnetic field is routinely monitored by magnetometers at the two sites, São Luís-SLZ and Vassouras-VSS $\left(3.89^{\circ} \mathrm{S}, 38.44^{\circ} \mathrm{W}\right.$, dip: -12.5$)$, at a rate of one measurement per second. In the present analysis, we have used a one-minute average of the $H$-component measurements from these two sites in order to determine the strength of the magnetic effect of the EEJ current at ground level (referred to as the EEJ ground strength, for simplification). The basic treatment of the magnetic data at each station is to eliminate outlier values from the measured components, based on a 3rd-order polynomial fitting. Thereafter, the five quietest days in a month are chosen and their local midnight values averaged. Then, the station $H$-component variations are normalized to the difference between the $H$ component values and the mean local midnight values for the five quietest days, providing the $\Delta H$ for that corresponding station. Finally, the variation of the EEJ ground strength $\left(\Delta H_{\mathrm{SLZ}}-\Delta H_{\mathrm{VSS}}\right)$ is estimated by taking the difference between the $\Delta H$ values at a station at the dip equator $\left(\Delta H_{\mathrm{SLZ}}\right)$ and that at a station nearby the dip equator, but outside the EEJ influence ( $\left.\Delta H_{\mathrm{VSS}}\right)$. A more detailed explanation of the magnetic data treatment, and about the use of the two stations, can be found in Denardini et al. (2009).

In order to investigate the probable cause of the observed enhancements, we looked for solar flare occurrences that matched with the time of occurrence of such enhancements at the $E$-region heights. Therefore, we used measurements of X-ray radiation in the range 1.0-8.0 $\AA$, made by X-ray Sensors (XRS) of the GOES 10 satellites (Geostationary Operational Environmental Satellites) located at 6.6 Earth's 
15 DEC $2006(349)$
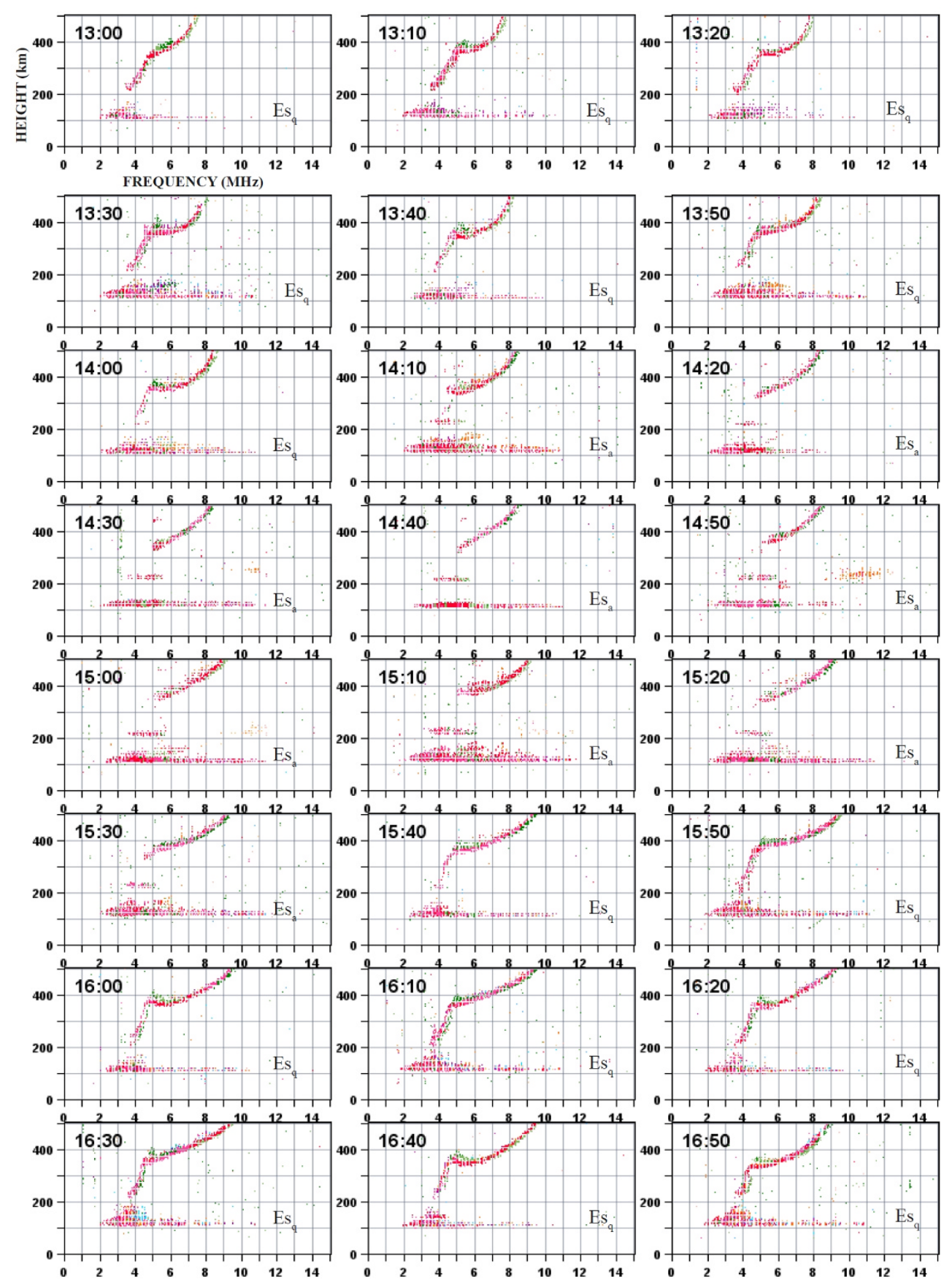

Fig. 2. Sequence of ionograms obtained at São Luís on 15 December, 2006, between 1300 and 2330 UT.

Radii (Aschwanden, 1994), to identify solar flare signatures (Taylor and Watkiks, 1970).

\section{Results and Discussions}

Figure 1 shows three panels with the variation of the $D_{\mathrm{st}}$ index (top), the variation of the $f_{\mathrm{b}} E_{\mathrm{s}}$ (green line) and $f_{\mathrm{t}} E_{\mathrm{s}}$ (brown line) at São Luís (middle), and the variation of the $\mathrm{X}$-ray solar radiation intensity measured in the range 1.08.0 Å (blue line) from December 12-18, 2006 (bottom). All the data are referred to in UT. The $D_{\text {st }}$ intensity variation is given in $\mathrm{nT}$ and its linear scale is shown by the left vertical axis of the top panel. Both $f_{\mathrm{b}} E_{\mathrm{s}}$ and $f_{\mathrm{t}} E_{\mathrm{s}}$ are given in $\mathrm{MHz}$ and their linear scale is shown in the left vertical axis of the middle panel. The X-ray solar radiation intensity is given in $\mathrm{W} / \mathrm{m}^{2}$ and its logarithmic scale is shown in the left vertical axis of the bottom panel. The right vertical axis of the bottom panel also shows a classification of the flare according to the intensity reached by the peak of the X-ray flux (Somov and Syrovatskii, 1972).

The typical behavior of $f_{\mathrm{t}} E_{\mathrm{s}}$ and $f_{\mathrm{b}} E_{\mathrm{s}}$ is characterized by enhancements during the morning period after about 9 UT up to maximum values attained at around $15 \mathrm{UT}$. They then decrease to quiescent values after about 21 UT. The baseline of $f_{\mathrm{t}} E_{\mathrm{s}}$ remains in the range between 4 and $6 \mathrm{MHz}$ dur- 


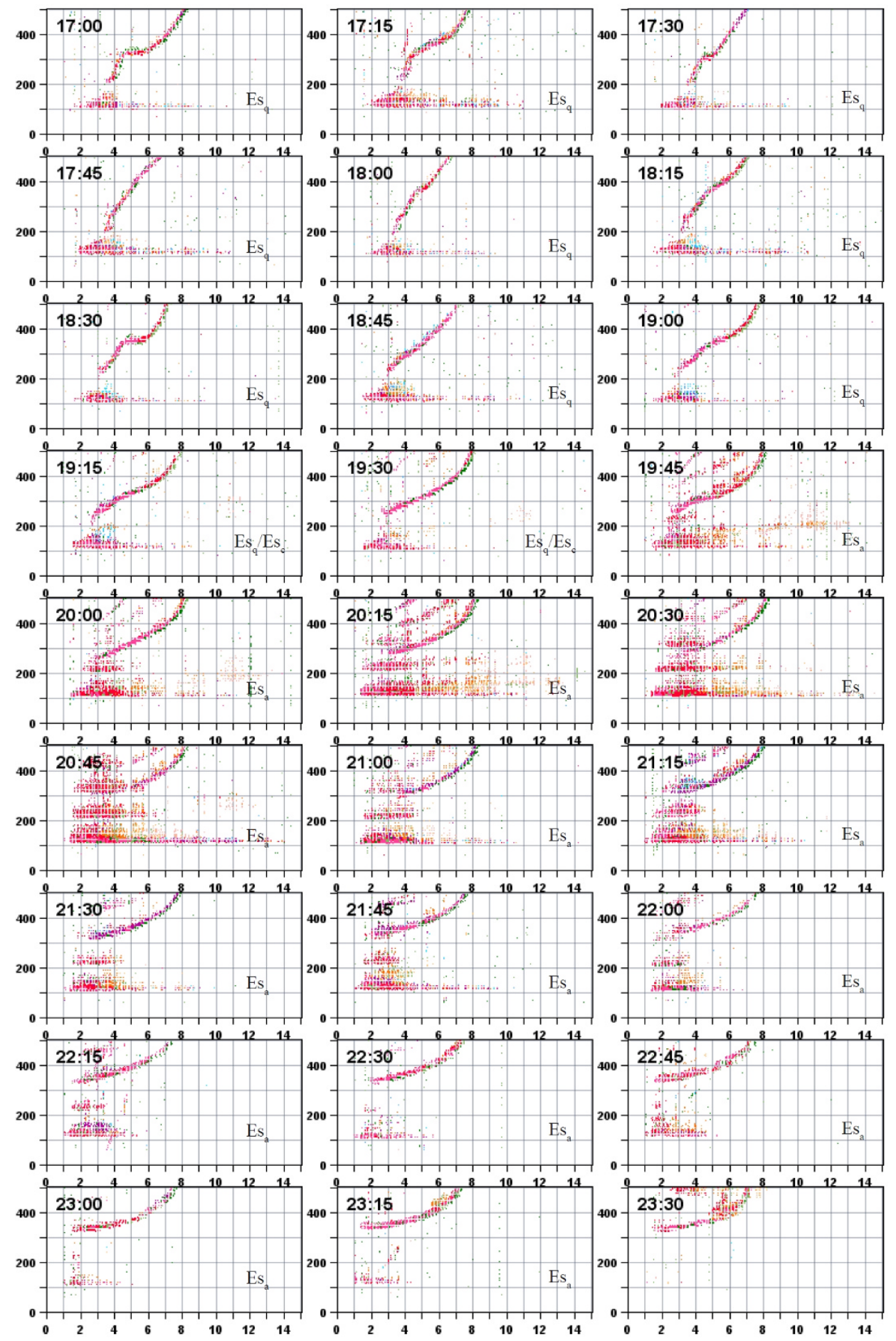

Fig. 2. (continued).

ing the selected days. Top values of $f_{\mathrm{t}} E_{\mathrm{s}}$ are about $11 \mathrm{MHz}$ at 13 UT. However, on December 15 and 16 , the $f_{\mathrm{t}} E_{\mathrm{s}}$ maximum peak value reached $15 \mathrm{MHz}$ (identified by red circles in the middle panel of Fig. 1). The $f_{\mathrm{b}} E_{\mathrm{s}}$ baseline remained around $1.5 \mathrm{MHz}$ in the morning period. After around $10 \mathrm{UT}$, this parameter rose to approximately $4 \mathrm{MHz}$ and started decreasing to the baseline value at 21 UT. Nevertheless, it is possible to identify peaks in the $f_{\mathrm{b}} E_{\mathrm{s}}$ that are superposed on this behavior. These significant increases of $f_{\mathrm{b}} E_{\mathrm{s}}$ are identified by arrows with capital letters A-E. All these peaks are observed during the recovery phase of the mag- netic storm that started on December 14. The first and second peaks (A and $\mathrm{B}$ ) reached $\sim 5 \mathrm{MHz}$ at $21 \mathrm{UT}$. At around $18 \mathrm{UT}$ on December 16 , the $f_{\mathrm{b}} E_{\mathrm{s}}$ reached $7.5 \mathrm{MHz}(\mathrm{C})$. On December 17, there occurred two peaks. The first (D) occurred during the morning (11 UT) and reached 3.5 MHz. The other peak occurred at $21 \mathrm{UT}$ (E) and achieved $5 \mathrm{MHz}$. Besides the occurrence of these peaks, a different type of $E_{\mathrm{s}}$ layer was detected during these observations.

The occurrence of these peaks during the recovery phase, and the simultaneous observations of different types of $E_{\mathrm{s}}$ layers, agrees with previous work by Batista and Abdu 


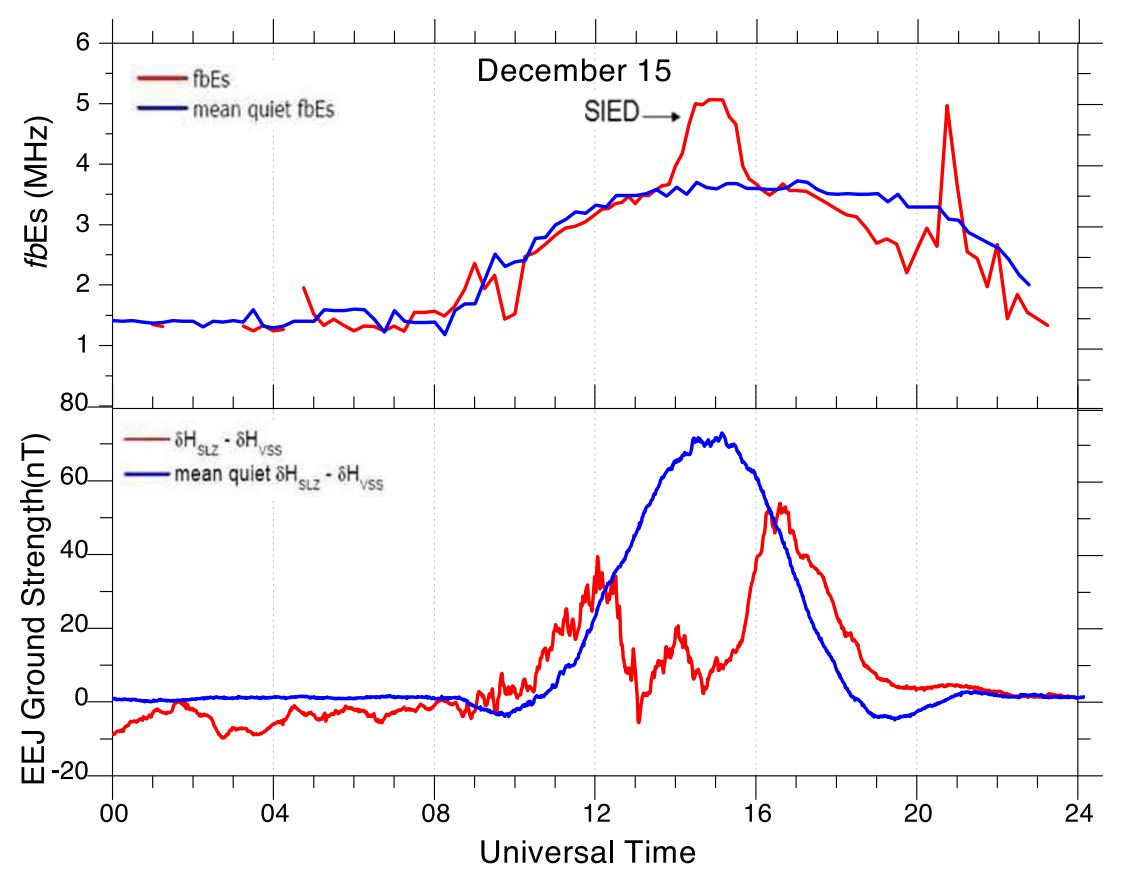

Fig. 3. Diurnal variation of the $f_{\mathrm{b}} E_{\mathrm{s}}$ (upper) and of the EEJ ground strength (below) on December 15 (red lines). The blue lines show the average derived from a quiet time period just before the magnetic storm.

(1977). They reported a study from geomagnetic storms in 1973 and in 1975 , in which $f_{\mathrm{b}} E_{\mathrm{s}}$ reached values greater than $7 \mathrm{MHz} 2-3$ days after the storms. At that time, they had classified some sporadic layers as being type "a" and, after a careful study of winds and recombination rate, they associated the increase of $f_{\mathrm{b}} E_{\mathrm{s}}$ to particle precipitations from the Van Allen Radiation Belt. In most of the cases in the present study, we also classified the different types of $E_{\mathrm{s}}$ layer observed with the occurrence of the peak as an "a" type. However, we associated the $E_{\mathrm{sa}}$ in our study with the wind shear superposed on the Gradient-Drift instability, instead of the precipitation of particles (Abdu, private communication, 2010).

In order to check our assumption, the peak which occurred on December 15 was carefully studied with the aim of investigating the EEJ dynamics. We have focused most of our attention on this peak because we have more data for this period. Unfortunately, we do not have enough ground magnetic data that exactly matches both the location and time of observations for the other highlighted peaks, or either they occurred during nighttime. However, we have found a similar behavior for other periods (not shown here) in an ongoing study. Figure 2 shows a sequence of ionograms obtained at São Luís between 1300 and 2330 UT. Here, it is possible to observe the presence of the $E_{\mathrm{sq}}$ (which, as mentioned before, are associated with the EEJ plasma irregularities) during most of the time. At 1410 UT, an $E_{\mathrm{sa}}$ was detected at $115 \mathrm{~km}$ and blocked all the reflections of the ionosonde signal at the upper portions of the ionospheric profile. It lasted until $1540 \mathrm{UT}$, when the $E_{\mathrm{sq}}$ trace replaced it. At $1915 \mathrm{UT}$, an $E_{\mathrm{sq}}$ and an $E_{\mathrm{sc}}$ appear together, and lasted until $1930 \mathrm{UT}$. After that, the $E_{\mathrm{sa}}$ reappeared, showing a clearer and stronger trace that blocked the observation of the upper layers one more time.

Aiming to explain the formation of the type "a" $E_{\mathrm{s}}$ layers, we also investigate the EEJ ground strength. Figure 3 shows a more detailed analysis of the specific case of the event of December 15. The top panel shows the variation of $f_{\mathrm{b}} E_{\mathrm{s}}$ during the disturbed period (red line) and an average $f_{\mathrm{b}} E_{\mathrm{s}}$ derived from digisonde data for some quiet days before the storm (blue line). The bottom panel shows the EEJ groundstrength variation as a function of UT from the disturbed periods that we are analyzing (red line) and an average EEJ ground strength derived for quiet days (Dec. 12-14) just before the storm (blue line). The $f_{\mathrm{b}} E_{\mathrm{s}}$ is given in $\mathrm{MHz}$ and the EEJ ground strength is given in nT. This figure clearly shows that the sudden increase in the electron density (SIED) on December 15 occurred during counter electrojet (CEJ) conditions. Moreover, the comparison of the time of occurrence of this peak (14-16 UT) with the events described in Fig. 2 indicates that the $E_{\mathrm{sa}}$ layer was probably generated as a result of the presence of this CEJ.

In fact, Reddy and Devasia (1981) and Devasia et al. (2006) have studied the dependence of the appearance of sporadic layers at an equatorial latitude on the cycle of solar activity. Denardini et al. (2009) show the occurrence of an $E_{\mathrm{s}}$ layer associated with CEJ for the same region as the present study. All the events that were reported during CEJ events occurred under magnetically quiet conditions. The appearance of the $E_{\mathrm{sa}}$ layer in our case occurred during a magnetic storm, however. The $D_{\text {st }}$ index was around $-70 \mathrm{nT}$.

During the recovery phase of the geomagnetic storm, the primary zonal electric field may be reversed to westward during the day, due to the ionospheric disturbance dynamo (IDD). Richmond et al. (2003) and Huang and Chen (2008) have shown that the disturbed zonal electric field caused by the IDD may not reverse the electric field during daytime, but it can drastically reduce it instead. Also, a sudden northward turning of the $B_{z}$ component of the solar wind 
may cause overshielding in the planetary electric field and create a Prompt Penetration Electric Field (PPEF), which may reverse, or reduce, the primary zonal electric field. However, PPEFs have a duration of about $30 \mathrm{~min}$ to $1 \mathrm{~h}$, and the SIED event we showed in the graph of the Fig. 3 lasted for almost $3 \mathrm{~h}$.

Therefore, the cause of the appearance of this sporadic layer, which is related to the sudden increase in the electron density in the $E$ region, is still an open question, although we tend to attribute it to a wind shear mechanism superposed on the Gradient-Drift instability. Moreover, due to the similar characteristics between our example and that reported by Reddy and Devasia (1981) and Devasia et al. (2006), we believe that the appearance of the sporadic layer results from the drastic reduction of the EEJ electric field, which we suppose is associated with neutral winds added to the IDD condition. Hence, a downward polarization electric field caused by the wind shear should be responsible for inverting the normal upward electric field in a constraint height range, contributing to the observed drastic reduction of the EEJ ground strength. Also, plasma irregularities in the upper portion of the sporadic layer may be detected (Crochet et al., 1979; Denardini et al., 2009).

In the present analysis, we also consider the influence on the X-ray radiation due to solar burst events. The bottom panel of Fig. 1 shows that the variation of the X-ray solar radiation intensity follows a similar behavior to the solarcycle activity, which results in periodic disturbances in the Earth's atmosphere and they are divided in the classes. Indeed, we have checked several cases of X-ray solar bursts associated with strong magnetic storms during solar cycle 23 (not shown here), including the present case. Most of the X-ray peaks $(\approx 65 \%)$ caused an absorption of radio waves with wavelengths compatible with those for $E$-region soundings. This radio wave absorption is attributed to Sudden Ionospheric Disturbances (SID), which occurred at the $D$-region height (Sahai et al., 2007), thereby not allowing us to observe the upper regions. Therefore, despite the fact that characteristics of high-intensity flares (X class) can be noted on the X-ray measurements at the GOES-10 satellite, we were not able to prove that these intensifications may affect the parameters of the $E_{\mathrm{s}}$ layer directly.

\section{Conclusions}

We have sought to identify the effect of solar activity on the density enhancement of $E_{\mathrm{s}}$-layers observed at São LuísMA, Brazil, during disturbed periods. In general, the $f_{\mathrm{t}} E_{\mathrm{s}}$ is characterized by a typical diurnal variation, when it does not exceed $13 \mathrm{MHz}$. However, we have shown that the $f_{\mathrm{t}} E_{\mathrm{s}}$ reached peak values of $15 \mathrm{MHz}$ on December 15 and 16 . We also showed $f_{\mathrm{b}} E_{\mathrm{s}}$ peaks superposed on the normal daily variation of this parameter. This also occurred during the recovery phase of the magnetic storm analyzed. The peak explored in the present work was associated with the presence of a sporadic layer type "a", the formation of which we attributed to wind shear superposed on the GradientDrift instability. The event, which occurred on December 15 , when $f_{\mathrm{b}} E_{\mathrm{s}}$ rose to $5 \mathrm{MHz}$, was carefully studied taking into account EEJ dynamics. On this day, the $E_{\mathrm{sa}}$ layer was detected at about $115 \mathrm{~km}$, between 1410 and $1540 \mathrm{UT}$, and blocked all the reflections of the ionosonde signal at the upper portions of the ionospheric profile. During this time, a CEJ is clearly identified from magnetometer measurements. Therefore, we attributed this ionization increase to conditions generated by the CEJ. In the present analysis, we also consider the influence on $\mathrm{X}$-ray radiation due to solar burst events. Our previous analyses revealed that $\mathrm{X}$-ray solar flux intensifications caused Sudden Ionospheric Disturbances (SID) that absorbed the radio wave at the $D$ region heights, not allowing us to observe the $E$-region. Therefore, we were not able to prove that these intensifications may affect the parameters in the $E_{\mathrm{s}}$ layer directly.

Acknowledgments. L. C. A. Resende thanks Capes/MEC for her $\mathrm{PhD}$ fellowship and C. M. Denardini thanks CNPq/MCT (Grants 305923/2008-0 and 470553/2009-0). The authors thank NOAA for making available the GOES satellite data.

\section{References}

Afraimovich, E. L., A. T. Altyntsev, E. A. Kosogorov, N. S. Larina, and L. A. Leonovich, Ionospheric effects of the solar flares of September 23, 1998 and July 29, 1999 as deduced from global GPS network data, $J$. Atmos. Sol.-Terr. Phys., 63, 1841-1849, 2001.

Aschwanden, M. J., Irradiance observations of the 1-8 $\AA$ soft X-ray flux from GOES, Sol. Phys., 152, 53-59, 1994.

Batista, I. S. and M. A. Abdu, Magnetic storm delayed sporadic E enhancements in the Brazilian geomagnetic anomaly, J. Geophys. Res., 82, 4777-4783, 1977.

Chimmonas, G., Enhancement of Sporadic-E by horizontal trans-port within the layer, J. Geophys. Res., 76, 4578-4586, 1971.

Cohen, R., W. Calvert, and K. L. Bowles, On the nature of equatorial slant Sporadic E, J. Geophys. Res., 67(A3), 965-972, 1962.

Crochet, M., P. Broche, and C. Hanuise, HF radar Studies of 2-stream instability during an equatorial counter-electrojet, J. Geophys. Res., 84, 203-204, 1979.

Denardini, C. M., M. A. Abdu, H. Aveiro, L. C. A. Resende, P. D. S. C. Almeida, E. P. A. Olivio, J. H. A. Sobral, and C. M. Wrasse, Counter electrojet features in the Brazilian sector: simultaneous observation by radar, digital sounder and magnetometers, Ann. Geophys., 24, 1593$1603,2009$.

Devasia, C. V., V. Sreeja, and S. Ravindran, Solar cycle dependent characteristics of the equatorial blanketing Es layers and associated irregularities, Ann. Geophys., 24, 2931-2947, 2006.

Fejer, B. G. and M. C. Kelley, Ionospheric irregularities, Rev. Geophys., 18, 401-454, 1980.

Forbes, J. M., The equatorial electrojet, Rev. Geophys., 19, 469-504, 1981. Hook, W. H., Ionospheric response to internal gravity waves 2 . Lower Fregion response, J. Geophys. Res., 75, 7229-7243, 1970.

Huang, C. M. and M. Q. Chen, Formation of maximum electric potential at the geomagnetic equator by the disturbance dynamo, J. Geophys. Res., 113, A03301, doi:10.1029/2007JA012843, 2008.

Jayachandran, P. T., Sequential Sporadic-E layers at low latitudes in the Indian sector, Ann. Geophys., 17, 519-525, 1991.

Knecht, R. W. and R. E. Mcduffie, Ionospheric Sporadic-E, J. Atmos. Sol.Terr. Phys., 14, 348, 1969.

Kopp, E., On the abundance of metal ions in the lower ionosphere, $J$. Geophys. Res, 102, 9667-9674, 1997.

Lanchester, B. S., T. Nygren, A. Huskomen, T. Turnen, and M. J. Jarvis, Sporadic-E as trace of atmospheric gravity waves, Planet. Space. Sci., 39, 1421-1434, 1991.

Piggot, W. and K. Rawer, Handbook of Ionogram Interpretation and Reduction, edited by US Department of Commerce, 352 pp., 1972.

Sahai, Y., F. Becker-Guedes, P. R. Fagundes, W. L. C. Lima, A. J. Abreu, F. L. Guarnieri, C. M. N. Candido, and V. G. Pillat, Unusual ionospheric effects observed during the intense 28 October 2003 solar flare in the Brazilian sector, Ann. Geophys., 25, 1904-1910, 2007.

Sauli, P. and A. Bourdillon, Height and critical frequency variations of the Sporadic-E layer at middle latitudes, J. Atmos. Sol.-Terr. Phys., 70, 2497-2502, 2008.

Somov, B. V. and S. I. Syrovatskii, Magnetically driven motions in solar corona, Soviet Phys., 34, 332-335, 1972. 
Reddy, C. A. and C. V. Devasia, Height and latitude structure of electric fields and currents due to local east-west winds in the equatorial electrojet, J. Geophys. Res., 86, 5751-5767, 1981.

Richmond, A. D., C. Peymirat, and R. G. Roble, Long-lasting disturbances in the equatorial ionospheric electric field simulated with a coupled magnetosphere-ionosphere-thermosphere model, J. Geophys. Res., 108(A3), 1118, 2003.

Taylor, G. N. and C. D. Watkiks, Ionospheric electron concentration enhancement during a solar flare, Nature, 228, 653-654, 1970.

Tsunoda, R. T., On blanketing sporadic-E and polarization effects near the equatorial electrojet, J. Geophys. Res., 113, A09304, doi:10.1029/2008JA013158, 2008.

Whitehead, J. D., Production and prediction of sporadic-E, Rev. Geophys. Space Phys., 8(1), 65-144, 1970.

Whitehead, J. D., Recent work on mid-latitude and equatorial Ssporadic-E, J. Atmos. Sol.-Terr. Phys., 51(5), 401-424, 1989.

L. C. A. Resende (e-mail: laysa@dae.inpe.br) and C. M. Denardini 